\title{
STRATEGI PENGEMBANGAN JERUK MANIS (Citrus sinensis, L) DI KECAMATAN BIREM BAYEUN KABUPATEN ACEH TIMUR
}

\author{
Supristiwendi ${ }^{1}$, Siti Balqies Indra ${ }^{2}$ dan Taufikal Hadi ${ }^{2}$ \\ ${ }^{1}$ Dosen Fakultas Pertanian Universitas Samudra \\ ${ }^{2}$ Dosen Fakultas Pertanian Universitas Samudra \\ ${ }^{2}$ Mahasiswa Program Studi Agribisnis Fakultas Pertanian Universitas Samudra
}

\begin{abstract}
ABSTRAK
Tujuan penelitian ini adalah untuk mengetahui Strategi Pengembangan Jeruk Manis di Kecamatan Birem Bayeun Kabupaten Aceh Timur. Penelitian ini dilaksanakan di Kecamatan Birem Bayeun Kabupaten Aceh Timur dengan menggunakan metode sensus. Objek penelitian ini adalah petani jeruk manis, dinas pertanian, penyuluh pertanian, ketua kelompok tani dan akademisi. Ruang lingkup penelitian ini dibatasi pada strategi pengembangan jeruk manis di kecamatan birem bayeun kabupaten aceh timur dengan analisis SWOT. Penelitian dilaksanakan pada bulan Mei 2018.

Jumlah petani sampel adalah sebanyak 15 orang dengan rincian Desa Alue Teh sebanyak 4 orang, Desa Jambo Labu 11 orang, 5 orang Sampel dari tokoh kunci ditentukan secara sengaja, dimana tokoh kunci sampel yang ditunjuk memang memiliki kompetensi di daerah penelitian. Tokoh kunci sebanyak 5 orang terdiri dari : Dinas Pertanian sebanyak 1 orang, Penyuluh Pertanian sebanyak 2 orang, Ketua Kelompok Tani sebanyak 1 orang dan Akademisi sebanyak 1 orang.

Hasil analisis SWOT strategi pengembangan jeruk manis di Kecamatan Birem Bayeun Kabupaten Aceh Timur adalah sebagai berikut: Mempertahankan kualitas jeruk manis dan meningkatkan hasil produksi, Memperluas lahan jeruk manis dengan memanfaatkan lokasi yang strategis dan kondisi lingkungan yang baik, Memanfaatkan Tenaga kerja yang ada untuk mengendalikan hama dan penyakit, Mempertahankan kualitas jeruk manis dan menjalin kerja sama yang baik dengan pelanggan tetap, Memanfaatkan lahan yang ada dan meningkatkan hasil produksi jeruk manis, Menjalin kerjasama dengan dinas pertanian untuk mengatasi kurangnya ketersediaan bibit dan lahan sehingga hasil produksi meningkat dan bisa mencukupi permintaan pasar, Meningkatkan perawatan jeruk manis sehingga masa produktif bisa panjang dan hama penyakit bisa dikendalikan, Menjalin kerjasama dengan dinas pertanian untuk mengatasi sulitnya didapat pestisida sehingga hama penyakit bisa dikendalikan. Melalui analisis QSPM, prioritas strategi yang di usulkan yaitu mempertahankan kualitas jeruk manis dan menjalin kerja sama yang baik dengan pelanggan tetap.
\end{abstract}

Kata Kunci: Jeruk manis, Strategi, Faktor Internal dan Eksternal, SWOT, Prioritas

\section{PENDAHULUAN}

Tanaman jeruk manis cocok ditanam di Kecamatan Birem Bayeun, karna kondisi tanah dan iklim yang sesuai sehingga memungkinkan untuk tumbuh, tanaman jeruk manis tidak memerlukan persyaratan tanah yang khusus hampir berbagai macam tanah dapat diusahakan untuk tanaman Jeruk manis. Drainase yang baik sangat perlu untuk memperoleh hasil yang tinggi.

Kecamatan Birem Bayeun adalah salah satu Kecamatan di Kabupaten Aceh Timur yang ada menanam tanaman jeruk manis disamping tanaman lainnya. Strategi adalah suatu bentuk atau rencana yang mengintegrasikan tujuan utama dalam suatu wilayah menjadi satu kesatuan yang utuh. Dengan demikian 
strategi hampir selalu dimulai dari apa yang dapat terjadi dan bukan dimulai dari apa yang terjadi. Misalnya strategi itu mengarahkan ke arah pengurangan biaya, perbaikan kualitas, dan memperluas pasar. Penyusunan strategi harus memperhatikan tujuan dan sasaran yang akan dicapai diwaktu yang akan datang, selain itu suatu kegiatan usahatani harus senantiasa berinteraksi dengan lingkungan dimana strategi tersebut dilaksanakan, sehingga strategi tersebut tidak bertentangan melainkan searah dan sesuai dengan kondisi lingkungan dan melihat kemampuan internal dan eksternal yang meliputi kekuatan dan kelemahan di wilayah tersebut.

Pengembangan adalah suatu usaha untuk meningkatkan teknis, teoritis dan konseptual yang bertujuan untuk meningkatkan usahatani yang sedang dijalankan melalui pendidikan dan pelatihan. Pengembangan dalam penelitian ini adalah pengembangan dalam usahatani jeruk manis. Strategi pengembangan adalah bakal tindakan yang menuntut keputusan manajemen puncak dalam pengembangan usahatani untuk merealisasikannya. Disamping itu, strategi pengembangan juga mempengaruhi kehidupan petani jeruk manis dalam jangka panjang, paling tidak selama lima tahun.

Melihat potensi usahatani jeruk manis sudah selayaknya dipikirkan strategi usahatani kedepan dengan mempertimbangkan faktor strategi internal dan eksternal. Faktor strategi internal mencakup faktor-faktor yang menjadi kekuatan dan kelemahan usahatani jeruk manis, sedangkan faktor strategi eksternal mencakup faktor-faktor yang menjadi peluang dan ancaman usahatani jeruk manis di Kecamatan
Birem Bayeun Kabupaten Aceh Timur. Berdasarkan uraian di atas maka penulis tertarik untuk melakukan penelitian tentang strategi pengembangan jeruk manis di Kecamatan Birem Bayeun Kabupaten Aceh Timur.

\section{Identifikasi Masalah}

Apa saja yang menjadi prioritas strategi dalam pengembangan usahatani jeruk manis di Kecamatan Birem Bayeun Kabupaten Aceh Timur?

\section{Tujuan Penelitian}

Untuk mengetahui prioritas strategi pengembangan jeruk manis di Kecamatan Birem Bayeun Kabupaten Aceh Timur.

\section{METODE PENELITIAN}

\section{Lokasi, Objek, Ruang Lingkup dan Waktu Penelitian}

Penelitian ini menggunakan metode survei. Objek penelitian ini adalah petani jeruk manis dan tokoh kunci yang ada di Kecamatan Birem Bayeun Kabupaten Aceh Timur. Ruang lingkup dalam penelitian ini dibatasi pada strategi pengembangan jeruk manis di Kecamatan Birem Bayeun Kabupaten Aceh Timur dengan analisis matriks SWOT (Strenghts, Weaknes, Opportunities, Treat). Penelitian dilaksanakan pada bulan April - Mei 2018.

\section{Teknik Penentuan Sampel}

Pengambilan sampel dilakukan dengan menggunakan metode sampling jenuh atau sensus. Jumlah sampel petani jeruk manis dalam penelitian ini adalah sama dengan jumlah populasi yang ada, selengkapnya dapat dilihat pada tabel dibawah ini :

Tabel III-1. Jumlah Populasi dan Jumlah Sampel Petani Jeruk Manis di Kecamatan Birem Bayeun Kabupaten Aceh Timur.

\begin{tabular}{|c|l|c|c|}
\hline No & \multicolumn{1}{|c|}{ Desa Sampel } & Populasi(Orang) & Sampel(Orang) \\
\hline 1 & Desa Alue The & 4 & 4 \\
2 & Desa Jambo Labu & 11 & 11 \\
\hline
\end{tabular}




\begin{tabular}{|c|c|c|c|}
\hline & Jumlah & 15 & 15 \\
\hline
\end{tabular}

Sumber : Data Primer, 2018 (diolah)

Dari tabel III-1 di atas dapat dilihat bahwa jumlah populasi dalam penelitian adalah sebanyak 15 orang. Jumlah sampel pada masing-masing desa yaitu Desa Alue Teh 4 orang dan Desa Jambo Labu 11 orang, sehingga jumlah sampel keseluruhan yaitu 15 orang.

Selanjutnya sampel dari tokoh kunci ditentukan secara sengaja, dimana tokoh kunci sampel yang ditunjuk memang memiliki kompentensi di daerah penelitian. Tokoh kunci sebanyak lima orang terdiri dari:
a. Dinas Pertanian sebanyak 1 orang
b. Penyuluh Pertanian sebanyak 2 orang
c. Ketua Kelompok Tani sebanyak 1 orang
d. Akademisi sebanyak 1 orang

\section{Teknik Pengumpulan Data}

Sumber data penelitian merupakan faktor penting yang menjadi pertimbangan dalam menentukan metode pengumpulan data. Data yang diambil dan dikumpulkan dalam penelitian ini terdiri dari data primer dan data sekunder.

\section{Model dan Metode Analisis}

1. Analisi EFI

Analisis EFI dilakukan untuk memperoleh faktor kekuatan yang dapat dimanfaatkan dan faktor kelemahan yang harus diatasi dengan matriks EFI.

2. Analisis EFE

Analisis EFE dilakukan untuk mengetahui seberapa baik strategi yang telah dilakukan untuk melihat peluang dan ancaman yang ada dengan matrik EFE.

3. Analisis matriks EFI atau EFE dan pembuatan matriks SWOT
Analisis matriks SWOT diperoleh dari matriks EFI dan EFE. empat strategi utama yang disarankan yaitu strategi SO (strengths and opportunities), WO (weakness and opportunities), ST (strengths and threats) dan WT (weakness and threats). Adapun hasil analisi matriks SWOT maka alternatif atau pilihan strategi yang tepat diberikan untuk pengembangan usahatani jeruk manis di Kecamatan Birem Bayeun Kabupaten Aceh Timur

4. Pengambilan keputusan dari berbagai alternatif strategi

Setelah diperoleh berbagai alternatif strategi melalui tahap pencocokan, yaitu dengan menggunakan matriks EFI atau EFE dan Matriks SWOT, maka tahap akhir dari analisis formulasi strategi adalah pemilihan strategi yang baik. Alternatif strategi yang memiliki STAS tertinggi akan menjadi prioritas tertinggi dalam mengembangkan usahatani jeruk manis di Kecamatan Birem Bayeun Kabupaten Aceh Timur, disusul alternatif strategi dengan nilai STAS di bawahnya sampai STAS terendeh.

\section{HASIL DAN \\ PEMBAHASA \\ N}

Inventarisasi dan Pembobotan Faktor-faktor Strategi Lingkungan Internal Kekuatan dan Kelemahan

Adapun faktor-faktor strategi internal yang menjadi kekuatan (Strengths) bagi pengembangan jeruk manis di Kecamatan Birem Bayeun Kabupaten Aceh Timur sebagai berikut: 
Tabel V-1. Faktor Kekuatan Pengembangan Jeruk Manis di Kecamatan Birem Bayeun Kabupaten Aceh Timur, 2018

\begin{tabular}{|l|l|l|c|}
\hline No & \multicolumn{1}{|c|}{ Pernyataan } & Total Skor & Rata-rata \\
\hline 1 & Jeruk manis yang dihasilkan baik & 88 & 4,40 \\
2 & Lokasi yang strategis & 84 & 4,20 \\
3 & Adanya tenaga kerja yang sudah ahli Adanya & 80 & 4,00 \\
4 & kerjasama dengan pelanggan tetap Kemampuan & 78 & 3,90 \\
5 & petani dalam melihat kondisi pasar & 72 & 3,60 \\
\hline & \multicolumn{1}{|c|}{ Total Rata-rata } & & 4,02 \\
\hline
\end{tabular}

Sumber: Data primer 2018, (diolah)

Tabel V-1 menjelaskan hasil pengisian kuisioner faktor internal kekuatan diperoleh total skor tertinggi pada pernyataan jeruk manis yang dihasilkan baik sebesar 88 skor dan total skor terendah pada pernyataan kemampuan petani dalam melihat kondisi pasar sebesar 72 skor. Total rata-rata skor jawaban atas pernyataan kekuatan adalah 4,02 Artinya bahwa responden Tabel V-2. Faktor Kelemahan Pengembangan Jeruk Manis di Kecamatan Birem Bayeun Kabupaten Aceh Timur, 2018

\begin{tabular}{|l|l|l|r|}
\hline No & \multicolumn{1}{|c|}{ Pernyataan } & Total Skor & Rata-rata \\
\hline 1 & Besarnya biaya awal usahatani jeruk manis yang 96 & 4,80 \\
2 & dikeluarkan & & \\
3 & Kurangnya ketersediaan bibit & Masa produktif jeruk manis yang tergolong singkat & 82 \\
4 & Sulitnya didapat pestisida untuk mengendalikan & 74 & 4,50 \\
& hama dan penyakit pada tanaman jeruk manis. & & 4,10 \\
5 & Kurangnya ketersediaan lahan & 60 & 3,70 \\
\hline & Total Rata-rata & & 3,00 \\
\hline
\end{tabular}

Sumber: Data primer 2018, (diolah)

Tabel V-2 menjelaskan hasil pengisian kuisioner faktor internal kelemahan diperoleh total skor tertinggi pada pernyataan besarnya biaya awal usahatani jeruk manis yang dikeluarkan sebesar 96 skor dan total skor terendah pada pernyataan kurangnya ketersediaan lahan sebesar 60 skor. Total rata-rata skor jawaban atas pernyataan kelemahan adalah 4,02 Artinya bahwa responden netral dan setuju untuk 5 pernyataan sebagai faktor kelemahan dalam pengembangan jeruk manis di Kecamatan Birem Bayeun. setuju untuk 5 pernyataan sebagai faktor kekuatan dalam pengembangan jeruk manis di Kecamatan Birem Bayeun.

Sedangkan faktor-faktor strategi internal yang menjadi kelemahan (weaknesses) bagi pengembangan jeruk manis di Kecamatan Birem Bayeun Kabupaten Aceh Timur adalah sebagai berikut: 
Kecamatan Birem Bayeun sebagai berikut :

Tabel V-3. Faktor Peluang pengembangan jeruk manis di Kecamatan Birem Bayeun Kabupaten Aceh Timur, 2018

\begin{tabular}{|l|l|l|r|}
\hline No & \multicolumn{1}{|c|}{ Pernyataan } & Total Skor & Rata-rata \\
\hline 1 & Dapat meningkatkan pendapatan petani jeruk manis & 92 & 4,60 \\
2 & Hasil produksi yang masih belum mencukupi & 89 & 4,45 \\
& $\begin{array}{l}\text { permintaan pasar } \\
3\end{array}$ & Banyaknya permintaan akan jeruk manis dipasaran & 86 \\
4 & Kondisi lingkungan yang baik & 83 & 4,30 \\
5 & Harga jual yang baik & 80 & 4,15 \\
\hline & Total Rata-rata & & 4,00 \\
\hline
\end{tabular}

Sumber: Data primer 2018, (diolah)

Tabel V-3 menjelaskan hasil pengisian kuisioner faktor eksternal peluang diperoleh total skor tertinggi pada pernyataan dapat meningkatkan pendapatan petani jeruk manis sebesar 92 skor dan total skor terendah pada pernyataan harga jual yang baik sebesar 80 skor. Total rata-rata skor jawaban atas pernyataan peluang adalah 4,30 Artinya bahwa responden setuju untuk 5 pernyataan sebagai faktor peluang dalam pengembangan jeruk manis di Kecamatan Birem Bayeun.

Sedangkan faktor-faktor strategi eksternal yang menjadi Ancaman (Treaths) bagi pengembangan jeruk manis di Kecamatan Birem Bayeun adalah sebagai berikut:

Tabel V-4. Faktor Ancaman Pengembangan Jeruk Manis di Kecamatan Birem Bayeun Kabupaten Aceh Timur, 2018

\begin{tabular}{|l|l|l|c|}
\hline No & \multicolumn{1}{|c|}{ Pernyataan } & Total Skor & Rata-rata \\
\hline 1 & $\begin{array}{l}\text { Banyaknya hama walangsangit yang menyerang } \\
\text { tanaman jeruk manis }\end{array}$ & 4,55 \\
2 & $\begin{array}{l}\text { Penyakit jamur batang yang menyerang tanaman } \\
\text { jeruk manis }\end{array}$ & 86 & 4,30 \\
3 & $\begin{array}{l}\text { Musim panas yang berkepanjangan } \\
4\end{array}$ & $\begin{array}{l}\text { Adanya jeruk manis dari daerah lain yang lebih } \\
\text { murah }\end{array}$ & 38 \\
5 & Adanya pencurian hasil produksi jeruk manis & 54 & 3,85 \\
\hline & \multicolumn{1}{|c|}{ Total Rata-rata } & 2,70 \\
\hline
\end{tabular}

Sumber: Data primer 2018, (diolah)

Tabel V-4 menjelaskan hasil pengisian kuisioner faktor eksternal ancaman diperoleh total skor tertinggi pada pernyataan banyaknya hama walangsangit yang menyerang tanaman jeruk manis sebesar 91 skor dan total skor terendah pada pernyataan Adanya

pencurian hasil produksi jeruk manis sebesar 54 skor. Total rata-rata skor jawaban atas pernyataan peluang adalah 3,85

Hasil matriks EFI dan EFE strategi pengembangan jeruk manis adalah sebagai berikut: 
Tabel V-5. Hasil Analisis Matrik EFI dan EFE

\begin{tabular}{|c|c|c|}
\hline EFI dan EFE & Kekuatan (S) & Kelemahan (W) \\
\hline Peluang $(\mathrm{O})$ & $\begin{array}{l}\text { Strategi }(\mathrm{SO}) \\
=2,173+2,353 \\
=4,526\end{array}$ & $\begin{array}{l}\text { Strategi }(\mathrm{WO}) \\
=0,669+2,353 \\
=3,022\end{array}$ \\
\hline Ancaman (T) & $\begin{array}{l}\text { Strategi }(\mathrm{ST}) \\
=2,173+0,584 \\
=2,757\end{array}$ & $\begin{array}{l}\text { Strategi }(\mathrm{WT}) \\
=0,669+0,584 \\
=1,253\end{array}$ \\
\hline
\end{tabular}

Sumber: Data primer 2018, (diolah)

Kesimpulannya adalah strategi SO memiliki skor tertinggi dibandingka strategi WO, ST, dan WT sehingga strategi pengembangan jeruk manis di Kecamatan Birem Bayeun memungkinkan untuk dilakukan.

\section{Analisis Matrik SWOT}

Analisis matrik SWOT menggunakan data yang telah diperoleh dari matriks EFI dan EFE. Empat strategi utama yang disarankan yaitu strategi SO (Strength and opportunities), WO (weakness and opportunities), ST (strength and threats) dan (weakness and threats).

\section{Pengambilan Keputusan}

Tahap pengambilan keputusan ini menggunakan Matriks Perencanaan Strategi Kuantitatif (Quantitative Strategic Planning Matrix/QSPM). Nilai AS (Attractiveness Score) atau skor ketertarikan menunjukkan daya tarik masing masing strategi terhadap faktor kunci internal dan eksternal. Kemudian dilanjutkan perhitungan nilai STAS (Sum Total Attractiveness Score) atau total keseluruhan skor ketertarikan dari masing-masing responden dengan cara menjumlahkan seluruh nilai TAS dari masing-masing faktor internal dan eksternal.

Tabel V-8 : Prioritas Strategi pada Pengembangan jeruk manis Di Kecamatan Birem Bayeun Kabupaten Aceh Timur,2018

\begin{tabular}{|l|c|c|c|c|c|c|c|c|}
\hline & Strategi & Strategi & Strategi & Strategi & Strategi & Strategi & Strategi & Strategi \\
\cline { 2 - 9 } & 1 & 2 & 3 & 4 & 5 & 6 & 7 & 8 \\
\hline STAS 1 & 5.177 & 5.811 & 5.736 & 5.930 & 6.113 & 5.810 & 5.806 & 5.364 \\
\hline STAS 2 & 5.441 & 5.533 & 5.593 & 5.987 & 5.647 & 5.577 & 5.678 & 5.457 \\
\hline STAS 3 & 5.539 & 5.419 & 5.532 & 5.614 & 5.618 & 5.579 & 5.116 & 5.121 \\
\hline STAS 4 & 5.991 & 5.341 & 5.442 & 5.403 & 5.013 & 5.311 & 5.238 & 5.156 \\
\hline STAS 5 & 5.637 & 5.669 & 5.572 & 5.557 & 5.183 & 5.722 & 5.449 & 5.530 \\
\hline Jumlah & 27.785 & 27.773 & 27.875 & 28.491 & 27.574 & 27.999 & 27.287 & 26.628 \\
\hline Rataan & 5.557 & 5.555 & 5.575 & 5.698 & 5.515 & 5.599 & 5.457 & 5.326 \\
\hline $\begin{array}{l}\text { Urutan } \\
\text { Perioritas } \\
\text { Strategi }\end{array}$ & $\mathbf{4}$ & $\mathbf{5}$ & $\mathbf{3}$ & $\mathbf{1}$ & $\mathbf{6}$ & $\mathbf{2}$ & $\mathbf{7}$ & $\mathbf{8}$ \\
\hline
\end{tabular}

Sumber: Data primer 2018, (diolah) 
Berdasarkan hasil perhitungan STAS rata-rata pada Tabel V-8 maka prioritas strategi terbaik yang dilakukan saat ini adalah Mempertahankan kualitas jeruk manis dan menjalin kerjasama yang baik dengan pelanggan tetap dengan STAS (Sum Total Attractiveness Score) rata-rata tertinggi sebesar 5,698. Adapun urutan prioritas strategi untuk pengembangan jeruk manis di Kecamatan Birem Bayeun adalah sebagai berikut:

a. Mempertahankan kualitas jeruk manis dan meningkatkan hasil produksi $($ STAS $=5,698)$

b. Memperluas lahan jeruk manis dengan memanfaatkan lokasi yang strategis dan kondisi lingkungan yang baik (STAS = 5,599)

c. Memanfaatkan Tenaga kerja yang ada untuk mengendalikan hama dan penyakit (STAS = 5,575)

d. Mempertahankan kualitas jeruk manis dan menjalin kerja sama yang baik dengan pelanggan tetap (STAS = 5,557)

e. Memanfaatkan lahan yang ada dan meningkatkan hasil produksi jeruk manis $($ STAS $=$ 5,555)

f. Menjalin kerjasama dengan dinas pertanian untuk mengatasi kurangnya ketersediaan bibit dan lahan sehingga hasil produksi meningkat dan bisa mencukupi permintaan pasar (STAS = 5,515)

g. Meningkatkan perawatan jeruk manis sehingga masa produktif bisa panjang dan hama penyakit bisa dikendalikan (STAS = 5,457)

h. Menjalin kerjasama dengan dinas pertanian untuk mengatasi sulitnya didapat pestisida sehingga hama penyakit bisa dikendalikan $($ STAS $=5,326)$

\section{KESIMPULAN DAN SARAN Kesimpulan}

Hasil analisis SWOT alternatif prioritas yang ditawarkan dalam rangka pengembangan jeruk manis di Kecamatan Birem Bayeun adalah :

1. Mempertahankan kualitas jeruk manis dan meningkatkan hasil produksi (STAS $=5,698$ )

2. Memperluas lahan jeruk manis dengan memanfaatkan lokasi yang strategis dan kondisi lingkungan yang baik (STAS = 5,599)

3. Memanfaatkan Tenaga kerja yang ada untuk mengendalikan hama dan penyakit (STAS = 5,575)

4. Mempertahankan kualitas jeruk manis dan menjalin kerja sama yang baik dengan pelanggan tetap (STAS $=5,557$ )

5. Memanfaatkan lahan yang ada dan meningkatkan hasil produksi jeruk manis $($ STAS $=5,555)$

6. Menjalin kerjasama dengan dinas pertanian untuk mengatasi kurangnya ketersediaan bibit dan lahan sehingga hasil produksi meningkat dan bisa mencukupi permintaan pasar $(\mathrm{STAS}=5,515)$

7. Meningkatkan perawatan jeruk manis sehingga masa produktif bisa panjang dan hama penyakit bisa dikendalikan (STAS $=5,457$ )

8. Menjalin kerjasama dengan dinas pertanian untuk mengatasi sulitnya didapat pestisida sehingga hama penyakit bisa dikendalikan $($ STAS $=5,326)$ 


\section{Saran}

1. Petani jeruk manis agar dapat mengolah usahataninya dengan lebih baik lagi agar hasil produksi bisa meningkat.

2. Berkoordinasi dengan Dinas terkait dalam pengembangan jeruk manis upaya meningkatan kesejahteraan masyarakat Kecamatan Birem Bayeun Kabupaten Aceh Timur.

3. Meningkatkan program pertemuan antara petani, dan penyuluhan pertanian upaya dalam menangani masalah perkembangan jeruk manis.

4. Diperlukan penelitian lanjutan mengenai tanaman jeruk manis agar diperoleh hasil penelitian yang dapat dijadikan pembanding terhadap penelitian ini.

\section{DAFTAR}

\section{PUSTAKA}

Ali Muhammad. 2003. Penelitian Pendidikan Prosedur dan Straregi. PustakaAlam. Jakarta. Anonimus, 2017. Potensi Wilayah. BPP Kecamatan Birem Bayeun, Kabupaten Aceh Timur.

David, 2002. Analisis SWOT, Teknik Pengumpulan Data dan Evaluasi, Grahamedia Pustaka, Jakarta.

David, Fred, R. 2004. Manajemen Strategi Konsep. PT. Indeks Kelompok Gramedia. Jakarta.

Nazir, Moh. 2005. Metode Penelitian. Cetakan ke V Ghalian Indonesia, Jakarta.

Pracaya. 2001. Jeruk Manis : Varietas, Budidaya dan Pascapanen. PT. Penebar Swadaya, Jakarta.

Rangkuti, Freddy. 2013. Analisis SWOT Teknik Membedah kasus Bisnis. Gramedia pustaka Utama, Jakarta.

Soelarso, B., 2001, Budidaya Jeruk Bebas Penyakit, Kanisius, Yogyakarta.
Sugiyono. 2008. Metode Penelitian Kualitatif dan $R \& D$. Alfabeta, Bandung. Tjitrosoepomo, G. 2004. Taksonomi Tumbuhan (Spermatophyta). UGM-Press, Yogyakarta.

Umar, Husein, 2001, Strategic Management In ActionCetakan Kelima. PT. Gramedia Pustaka Utama, Jakarta.

Zulkarnaen, H. O. dan Sutopo. 2013. Analisis Strategi Pemasaran Pada Usaha Kecil Menengah (UKM) Makanan ringan (studi penelitian UKM Snack Barokah Di Solo). Jounal of Management 2 (3): 1-13, UNDIP. Semarang. 